\begin{tabular}{|l|l|}
\hline SITAS & JANHUS Journal of Animal Husbandry Science \\
\hline Jurnal IImu Peternakan \\
Fakultas Pertanian, Universitas Garut \\
ISSN : 2548-7914
\end{tabular}

\title{
PENGARUH LAMA THAWING TERHADAP KUALITAS SPERMATOZOA SEMEN BEKU SAPI BALI (Bos sondaicus) di DINAS PERTANIAN PROVINSI MALUKU UTARA
}

\section{(Effect of Thawing Time on the Quality of Frozen Semen Spermatozoa of Bali Cattle (Bos sondaicus) In Agricultural Department of North Maluku)}

\author{
Fifi Andrefani, Oktora Dwi Putranti ${ }^{2}$, dan Abdurahman Hoda ${ }^{3}$ \\ ${ }^{1,2,3}$ Fakultas Pertanian, Program Studi Peternakan Universitas Khairun Ternate \\ Email : \\ ${ }^{1}$ fifiandrefani07@gmail.com \\ ²oktora.unkhair@gmail.com
}

\begin{abstract}
Abstrak
Penelitian ini dilaksanakan di Dinas Pertanian Provinsi Maluku Utara (Sofifi). Tujuan dari penelitian ini untuk mengetahui pengaruh lama thawing terhadap kualitas semen beku Sapi Bali. Analisis data yang digunakan dalam penelitian ini menggunakan Anlisis Of Variance (ANOVA) satu arah dengan empat macam perlakuan yaitu 15, 30, 45 dan 50 detik menggunakan air ledeng (PDAM) temperature $25-30^{\circ} \mathrm{C}$ dan dilakukan 4 kali ulangan. Perlakuan pada penelitian ini yaitu P1: thawing 15 detik, P2: thawing 30 detik, P3: thawing 45 detik, dan P4: thawing 50 detik. Parameter yang diamati pada penelitian ini adalah Motilitas, Viatabilitas, dan Abnormalitas. Hasil menunjukkan nilai terbaik Motilitas pada 15 detik sebesar 86,25\%. Viatabilitas sebesar 83,75\%. Sedangkan pada Abnormalitas thawing 15 detik memiliki nilai yang lebih rendah sebesar $15,00 \%$. Berdasarkan hasil penelitian dapat disimpulkan bahwa lama thawing 15 detik dan 30 detik mempunyai kualitas sperma yang lebih baik daripada lama thawing 45 dan 50 detik.
\end{abstract}

Kata Kunci : Thawing, Motilitas, Viatabilitas, dan Abnormalitas.

\begin{abstract}
This research was carried out in the agricultural department of North Maluku Province (Sofifi). The purpose of this study was to determine the effect of thawing time on the quality of Bali frozen semen. Analysis of the data used in this study used an one-way analysis of variance (ANOVA) with four types of treatments, namely 15 seconds, 30,45, and 50 seconds using tap water (PDAM) temperature of $25-30^{\circ} \mathrm{C}$ and carried out 4 replications. This research is: P1: 15 seconds thawing, $P 2: 30$ seconds thawing, $P 3: 45$ seconds thawing, and P4: 50 seconds thawing. The parameters observed in this study were motility, viatability, and abnormalities. The results showed the best value of motility at 15 seconds at $86.25 \%$. Viatability is $83.75 \%$. Whereas the 15 second thawing abnormality has a lower value of $15.00 \%$. Based on the results of the study it can be concluded that the length of thawing 15 seconds and 30 seconds has better sperm quality than the thawing duration of 45 and 50 seconds.
\end{abstract}

Keywords : Thawing, Motility, Viatability, and Abnormalities. 


\section{Pendahuluan}

Peningkatan produktifitas ternak sapi dibutuhkan bioteknologi di bidang Inseminasi Buatan (IB). IB merupakan suatu cara untuk memasukan semen (sperma) yang telah dicairkan dan telah diproses terlebih dahulu yang berasal dari ternak jantan ke saluran alat kelamin betina dengan menggunakan metode dan alat khusus yang disebut insemination gun. Inseminasi buatan merupakan metode yang tepat dan dapat diterima secara luas oleh masyarakat (Solihati dan Kune, 2009).

Keberhasilan IB salah satunya adalah kualitas semen dari pejantan unggul yang berkaitan erat dengan kualitas spermatozoa. Kualitas spermatozoa dipengaruhi oleh faktor internal (umur, bangsa dan genetik) maupun faktor eksternal (pakan, lingkungan, dan pengencer yang digunakan seperti air ledeng/PDAM). Semen yang umum digunakan untuk melakukan inseminasi yaitu semen beku dan semen cair, namun semen beku memiliki daya simpan yang lebih lama dibandingkan dengan semen cair (Wijayanti dan Simanjuntak, 2006).

Thawing merupakan pencairan kembali semen yang telah dibekukan sebelum dilakukan inseminasi. Suhu dan lama thawing mempunyai pengaruh besar terhadap keadaan spermatozoa khususnya keutuhan spermatozoa dalam semen. Kombinasi suhu dan lama thawing yang baik adalah yang dapat mencegah khususnya spermatozoa sehingga tetap memiliki kemampuan membuahi ovum yang tinggi. Keberhasilan thawing $40 \%$ dan presentase yang abnormal maksimal 10\% (Toelihere, 1993).

Kegagalan inseminasi buatan sering disebabkan kerna kurang diperhatikan waktu thawing yang tepat oleh inseminator. Sehingga perlu dilakukan uji kualitas semen beku dengan lama waktu thawing agar dapat mencegah penurunan kualitas spermatozoa sehingga tetap memiliki kemampuan membuahi ovum yang tinggi. Fertilisasi akan terganggu apabila abnormalitas primer mencapai $18-20 \%$ (Arifiantini dkk, 2006).

\section{Metodologi}

\subsection{Waktu dan Tempat}

Penelitian ini telah dilaksanakan selama tiga bulan mulai dari bulan Febuari sampai April 2018. Pada Dinas Pertanian Provinsi Maluku Utara di Sofifi.

\subsection{Bahan dan Metoda Penelitian}

\section{Bahan dan Alat Penelitian}

Bahan yang digunakan dalam penelitian ini adalah semen beku sapi Bali, eosin negrosin, cover glass, alkohol, tisu, kapas, kertas label, kertas lakmus, spirtus, korek api dan air. Alat yang 
digunakan antara lain: termometer, mikroskop, object glass, pipet tetes, stopwactch, kontainer, gunting, dan kamera.

\section{Metode Penelitian}

Semen beku yang digunakan dalam penelitian ini adalah semen beku sapi Bali yang ada di Dinas Pertanian Propinsi Maluku Utara (Sofifi). Semen beku yang digunakan berasal dari Balai Inseminasi Buatan Lembang dan Singoari. Sperma segar diencerkan dengan tris kuning telur atau Skim, diekuilibrasi pada temperature $5^{\circ} \mathrm{C}$ selama 2 jam, kumudian dikemas dalam straw dengan ukuran $0,25 \mathrm{ml}$, ujung straw ditutup, dan diekulibrasi $4-5^{\circ} \mathrm{C}$ selama 3 jam, selanjutnya diletakkan dalam styrofoam dalam uap nitrogen cair selama 10 menit dan dimasukkan dalam nitrogen cair ($196^{\circ} \mathrm{C}$ ) untuk penyimpanan.

\section{Parameter yang Diukur}

Parameter yang diukur dalam penelitian ini antara lain:

1. Motilitas

2. Viatabilitas

3. Abnormalitas

\section{Analisis Data}

Analisis data yang digunakan dalam penelitian ini menggunakan Anlisis Of Variance (ANOVA) satu arah. Apabila terdapat perbedaan yang nyata $(\mathrm{P} \leq 0,05)$, maka dilanjutkan dengan uji TukeyProsedur dengan SPSS 16 (Hartono,2008).

\section{$3 \quad$ Hasil dan Pembahasan}

\section{Motilitas Spermatozoa}

Hasil analisis Tukey (pada Tabel 4) memperlihatkan bahwa perlakuan 15 dan 30 detik dengan lama thawing berbeda nyata $(\mathrm{P}<0,05)$ terhadap motilitas sperma sapi Bali.

Tabel 1. Hasil Analisis Motilitas Spermatozoa Semen Beku Sapi Bali (Rataan \pm SD)

\begin{tabular}{lllll}
\hline \multirow{2}{*}{ Parameter } & \multicolumn{4}{c}{ Lama Thawing (detik) } \\
\cline { 2 - 5 } & \multicolumn{2}{c}{15} & \multicolumn{4}{c}{30} & 45 & 50 \\
\hline $\mathrm{pH}$ & $7,0^{\mathrm{a}}$ & $7,0^{\mathrm{a}}$ & $7,0^{\mathrm{a}}$ & $7,0^{\mathrm{a}}$ \\
Motilitas $(\%)$ & $86,25 \pm 2,5^{\text {a }}$ & $78,75 \pm 9,46^{\text {a }}$ & $65,00 \pm 00^{\mathrm{b}}$ & $65 \pm 00^{\mathrm{b}}$ \\
\hline
\end{tabular}

${ }^{\mathrm{ab}}$ Superskip yang berbeda pada baris yang sama menunjukkan perbedaan nyata $(\mathrm{P}<0,05)$

Hal ini disebakan karena sperma sapi Bali adalah sperma yang sudah dewasa atau sudah cukup umur. Data hasil penelitian di atas menunjukkan bahwa semen beku yang digunakan memenuhi 
syarat untuk disimpan dan di inseminasikan, pada semen beku sapi Bali mempunyai nilai tertinggi pada perlakuan lama thawing selama 15 detik yaitu $86,25 \pm 2,5 \%$ (Tabel 1). Motilitas spermatozoa minimal 40\%. Arifiantini dkk (2006) melaporkan motilitas spermatozoa pada sapi FH dengan menggunakan pengencer kacang kedelai (KK), tris sukrosa (TS) dan tris masing-masing 50,20 \pm 7,$07 ; 46,04 \pm 3,54$; dan 43,02 $\pm 7,68 \%$.

Perlakuan metode thawing pada semen beku sapi Bali berpengaruh terhadap motilitas spermatozoa $(\mathrm{P}<0,05)$. Evaluasi motilitas spermatozoa post thawing adalah salah satu parameter yang banyak digunakan untuk menentukan kualitas semen sapi yang akan digunakan untuk menentukan kualitas semen sapi yang akan digunakan untuk inseminasi buatan. Syarat minimal motilitas semen post thawing agar semen dapat dipergunakan dalam inseminasi buatan adalah 40\% (Garner dan Hafez, 1993 dalam Oktora, 2017).

Thawing yang dilakukan dengan suhu $29^{\circ} \mathrm{C}$ selama 15 detik dan 30 detik memperlihatkan persentase motilitas yang lebih tinggi $86,25 \pm 2,5 ; 78,75 \pm 9,46 \%(\mathrm{P}<0,05)$ dibandingkan pada thawing selama 45 dan 50 detik, sedangkan pada thawing 15 dan 30 detik tidak berbeda $(\mathrm{P}<0,05)$. Diduga pada perlakuan tersebut metabolisme spermatozoa berjalan sempurna karena sesuai dengan suhu fisiologis yang normal pada sapi bali, pada suhu fisiologis, aktivitas reaksi enzimatik yang berlangsung selama metabolisme sel berlangsung optimal.

\section{Spermatozoa Hidup}

Rataan persentase spermatozoa sapi Bali dengan lama thawing yang berbeda disajikan pada tabel 2.

Tabel 2. Hasil Analisis Viatabilitas Semen Beku Sapi Bali (Rataan \pm SD)

\begin{tabular}{|c|c|c|c|c|}
\hline \multirow[t]{2}{*}{ Parameter } & \multicolumn{4}{|c|}{ Lama Thawing (detik) } \\
\hline & 15 & 30 & 45 & 50 \\
\hline $\mathrm{Ph}$ & $7,0^{\mathrm{a}}$ & $7,0^{\mathrm{a}}$ & $7,0^{\mathrm{a}}$ & $7,0^{\mathrm{a}}$ \\
\hline Sperma Hidup $(\%)$ & $83,75 \pm 13,35^{\mathrm{a}}$ & $78,75 \pm 16,64^{\mathrm{a}}$ & $72,5 \pm 18,35^{\mathrm{a}}$ & $70 \pm 2,16^{\mathrm{a}}$ \\
\hline
\end{tabular}

${ }^{a b}$ Superskip yang berbeda pada baris yang sama menunjukkan perbedaan nyata $(\mathrm{P}<0,05)$.

Hasil penelitian di atas (pada Tabel 2) menunjukkan bahwa viatabilitas pada tingkat thawing yang berbeda tidak berpengaruh pada spermatozoa hidup sapi Bali. Namun, thawing 15 detik memiliki nilai yg lebih tinggi dibandingkan dengan perlakuan lama thawing lainnya. pada lama thawing 15 detik tidak berbeda $(\mathrm{P}>0,05)$ dibandingkan dengan lama thawing 30 detik, namun lebih tinggi $(\mathrm{P}<0,05)$ dibandingkan dengan lama thawing 45 detik dan 50 detik. Hal ini menunjukkan bahwa spermatozoa mampu menjaga stabilitas ion dalam intraseluler sehingga keseimbangan metabolisme dalam sel berjalan dengan normal (Sayoko dkk, 2007).

Thawing yang dilakukan pada 15 detik, 30 detik, dan 45 detik memperlihatkan persentase viatabilitas yang lebih tinggi $(\mathrm{P}<0,05)$ dibandingkan pada thawing selama 50 detik. Sedangkan pada thawing $15,30,45$, dan 50 detik tidak berpengaruh nyata $(\mathrm{P}>0,05)$. Angka persentase pengamatan 
terbaik pada thawing 15,30 , dan 45 detik menghasilkan nilai pengamatan viatabilitas yang tinggi yaitu $83,75 \pm 13,35 ; 78,75 \pm 16,64$; dan $72,50 \pm 18,35 \%$. Hasil tersebut menunjukkan waktu 15 detik memiliki nilai lebih baik sesuai pernyataan Arifiantini (2012) bahwa waktu thawing tidak boleh lebih dari 15 detik.

\section{Abnormalitas Spermatozoa}

Morfologi sperma adalah bentuk sperma yang terdiri atas kepala dan ekor. Evaluasi morfologi sangat penting karena mengindikasikan proses spermatogenesis berjalan normal. Data abnormalitas ditunjukkan pada Tabel 3.

Tabel 3. Hasil Analisis Abnormalitas Semen Beku Sapi Bali (Rataan \pm SD)

\begin{tabular}{lllll}
\hline \multirow{2}{*}{ Parameter } & \multicolumn{4}{c}{ Lama Thawing (detik) } \\
\cline { 2 - 5 } & \multicolumn{1}{c}{15} & \multicolumn{4}{c}{30} & \multicolumn{1}{c}{50} \\
\hline $\mathrm{pH}$ & $7,0^{\mathrm{a}}$ & $7,0^{\mathrm{a}}$ & $7,0^{\mathrm{a}}$ & $7,0^{\mathrm{a}}$ \\
Abnormalitas$(\%)$ & $15,00 \pm 11,74^{\mathrm{a}}$ & $19,25 \pm 15,84^{\text {a }}$ & $24,00 \pm 8,67^{\mathrm{a}}$ & $26,75 \pm 13,88^{\mathrm{a}}$ \\
\hline
\end{tabular}

${ }^{\mathrm{ab}}$ Superskip yang berbeda pada baris yang sama menunjukkan perbedaan nyata $(\mathrm{P}<0,05)$

Data di atas menunjukkan bahwa abnormalitas pada tingkat thawing yang berbeda tidak berpengaruh pada abnormalitas spermatozoa sapi Bali (pada Tabel 6). Namun, thawing 15 detik memiliki nilai yang lebih rendah di bandingkan dengan lama thawing lainnya. pada lama thawing 30 detik lebih rendah $(\mathrm{P}>0,05)$ dibandingkan dengan 45 detik. Namun tidak berbeda $(\mathrm{P}>0,05)$ dengan lama thawing 50 detik.

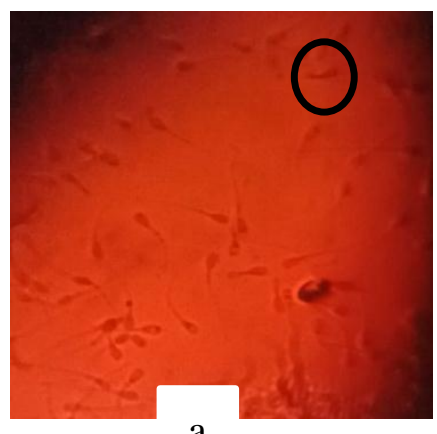

a

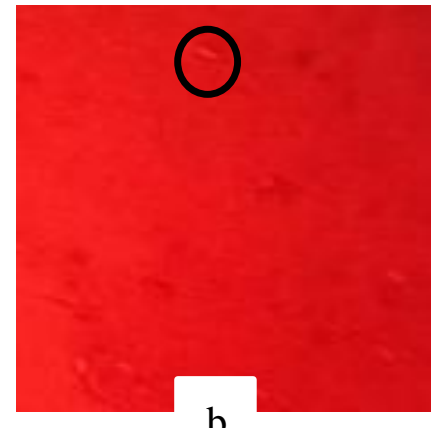

b

Gambar 3. Morfologi spermatozoa sapi bali

a.) Bentuk morfologi abnormalitas spermatozoa ekor melingkar.

b.) Bentuk morfologi abnormalitas spermatozoa kepala terputus

Abnormalitas ekor berbentuk melingkar atau terdapat patahan sering disebut simple bent tail. Abnormalitas simple bent tail menyebabkan sperma tidak dapat bergerak progresif ke depan hanya bergerak melingkar di tempat (Putranti, 2016). Sperma yang bergerak di tempat tentu saja tidak 
dapat membuahi oosit, karena pembuahan dapat terjadi bila sperma utuh bergerak progresif sehingga mampu membuahi oosit. Sperma yang terputus kepala dan ekor tentu saja tidak dapat membuahi karena tidak ada ekor yang menggerakan untuk menuju sel telur. Tanpa memandang abnormalitas primer maupun sekunder, sperma dapat mebuahi sel telur apabila abnormalitas sperma kurang dari 20\% (Soeparna dan Nurcholidah, 2014).

\section{$4 \quad$ Kesimpulan dan Saran}

\section{Kesimpulan}

Berdasarkan hasil penelitian dapat disimpulkan bahwa lama thawing 15 detik dan 30 detik mempunyai kualitas sperma yang lebih baik daripada lama thawing 45 dan 50 detik.

\section{Saran}

Berdasarkan hasil penelitian dapat dikemukakan beberapa saran sebagai berikut Perlu dilakukan penelitian lanjutan pada spermatozoa sapi yang berbeda dan sebagai sarana pelaksanaan IB, peneliti menyarankan bahwa waktu efektif untuk thawing pada semen beku sapi bali berkisar antara 1 menit (15 detik) dengan menggunakan air ledeng yang suhunya berkisar antara $25-30^{\circ} \mathrm{C}$.

\section{$5 \quad$ Daftar Pustaka}

Arifiantini, I. Wresdiyati, T dan Retnani, E. F. 2006. Kajian Banding Morfometri Sperma Sapi Bali (Bos sondaicus) Menggunakan Pewarnaan Williams, Eosin, Eosin Nigrosin dan Formol Saline. J Sain Vet

Arifiantini I. 2012. Teknik Koleksi dan Evaluasi Semen pada Hewan. PT Penerbit IPB Press. Bogor

Garner, D.L., E. and S. E. Hafez. 2000. Spermatozoa and seminal plasma. In: Reproduction in Farm Animals. $7^{\text {th }}$ Ed B Hafez/ESE Hafez. Lipponcott Williams \& Wilkins.USA.96-109.

Hartono. 2008. Teori Partofolio dan Analisis Investasi Edisi Kelima. BPFE. Yogyakarta.

Putranti,O.D. 2016. Disertasi. Pengaruh Penambahan Kafein Pada Sperma Kauda Epididimis Sapi Bali Pasca Thawing Terhadap Fertilitas Secara Fertilisasi In Vitro. Universitas Padjadjaran.

Soeparna dan Nurcholidah, S. 2014. Ilmu Reproduksi Ternak. Institut Pertanian Bogor Press

Sayoko Y, M Hartono, dan PE Silotonga. 2007. Faktor-faktor yang Mempengaruhi Persentase Spermatozoa Hidup Semen Beku Sapi pada Berbagai Inseminator di Lampung Tengah. Kumpulan Abstrak Skripsi Jurusan Produksi Ternak. Universitas Lampung. 
Vol. 3; No. 2; Juni 2019

Halaman 11-17

Solihati Nurcholidah dan Kune Petrus, 2009. Pengaruh jenis pengencer terhadap motilitas dan daya tahan hidup spermatozoa semen cair sapi Simmental. Fakultas Peternakan Universitas Padjadjaran. Bandung.

Toelihere, M.R., 1993. Inseminasi Buatan pada Ternak, Angkasa, Bandung.

Wijayanti Gratiana E. dan Simanjuntak Sorsa B.I. 2006. Viabilitas sperma ikan Nilem (Osteochilus hasselti C.V.) setelah penyimpanan jangka pendek dalam larutan ringer. 2:207-214. 